\title{
Focal segmental glomerulosclerosis following the Pfizer-BioNTech COVID-19 vaccine
}

\author{
Cho A Lim ${ }^{1}$, Hyun Soon Lee ${ }^{2}$, Songuk Yoon ${ }^{1}$, Eun Jung Kim리 Jang Won Seo ${ }^{1}$, Ja-Ryong Koo ${ }^{1}$, Seon Ha Baek ${ }^{1}$ \\ ${ }^{1}$ Division of Nephrology, Department of Internal Medicine, Hallym University Dongtan Sacred Heart Hospital, Hwaseong, Republic of Korea \\ ${ }^{2}$ Hankook Renal Pathology Lab, Seoul, Republic of Korea
}

Coronavirus disease 2019 (COVID-19) vaccines have shown excellent safety profiles. The most common short-term side effects are injection site reactions, fever, fatigue, and headache, while severe adverse reactions have rarely been reported [1]. However, since mass-scale vaccination began, several immune-mediated reactions (including myocarditis and de novo or relapsed glomerulonephritis [GN]) have been reported [1]. COVID-19 vaccines have also been reported to induce T-cell activation [2]. In this regard, the occurrence of kidney disease following administration of a COVID-19 vaccine can be related to the T-cell-mediated immune response it generates to viral messenger RNA (mRNA), which can trigger podocyte injury [2]. Herein, we report a case of focal segmental glomerulosclerosis (FSGS) with segmental lobular collapse and podocyte proliferation following vaccination with the first dose of the Pfizer-BioNTech COVID-19 vaccine that mimicked the cellular lesions of FSGS.

A previously healthy 29-year-old man visited our hospital with complaints of edema and decreased urine output that had occurred 7 days previously. He had received a COVID-19 vaccine 2 weeks prior (Fig. 1). He had also undergone a health checkup 3 months before the visit, including urinalysis and renal function testing, which showed no abnormalities.
Upon physical examination, the patient was afebrile with a blood pressure of $140 / 80 \mathrm{mmHg}$, and there was noticeable edema. He had gained $10 \mathrm{~kg}$ (from $83 \mathrm{~kg}$ to $93 \mathrm{~kg}$ ) within 1 week. Urinalysis showed the following results: protein, 4+; glucose, negative; red blood cells (RBCs), 10 to 19 per high-power field; and white blood cell (WBC) count, 1 to 4 per high-power field. Further evaluation showed WBC count, $6,800 / \mathrm{mm}^{3}$; hemoglobin, $15.6 \mathrm{~g} / \mathrm{dL}$; platelet count, $277,000 / \mathrm{mm}^{3}$; serum creatinine, $1.24 \mathrm{mg} / \mathrm{dL}$; total protein, $4.7 \mathrm{~g} / \mathrm{dL}$; albumin, $2.5 \mathrm{~g} / \mathrm{dL}$; total cholesterol, $351 \mathrm{mg} / \mathrm{dL}$; spot urine protein-to-creatinine ratio, $6.12 \mathrm{~g} / \mathrm{g}$; serum kappa-to-lambda light chain ratio, 0.79; serum complement C3, $144 \mathrm{mg} / \mathrm{dL}$; and serum complement C4, $65 \mathrm{mg} / \mathrm{dL}$. Additionally, the patient had negative serologic testing results for hepatitis $\mathrm{B}$, hepatitis $\mathrm{C}$, human immunodeficiency virus, anti-glomerular basement membrane antibody, rheumatoid factor, fluorescent antinuclear antibody, antineutrophil cytoplasmic antibody, anti-phospholipase A2 receptor-immunoglobulin G, and lupus anticoagulant. The screening test for COVID-19 was also negative.

A kidney biopsy was performed 31 days after the patient received his COVID-19 vaccination. Under light microscopy, the glomeruli were diffusely enlarged and hypercellular into the mesangium. Of the 20 glomeruli submitted, one

Received: December 24, 2021; Revised: January 4, 2022; Accepted: January 13, 2022

Correspondence: Seon Ha Baek

Division of Nephrology, Department of Internal Medicine, Hallym University Dongtan Sacred Heart Hospital, 7 Keunjaebong-gil, Hwaseong 18450, Republic of Korea. E-mail: seonhabaek@hallym.or.kr, haya2001@hanmail.net

ORCID: https://orcid.org/0000-0002-4751-9817

Copyright (C) 2022 by The Korean Society of Nephrology

(a) This is an Open Access article distributed under the terms of the Creative Commons Attribution Non-Commercial and No Derivatives License (http:// creativecommons.org/licenses/by-nc-nd/4.0/) which permits unrestricted non-commercial use, distribution of the material without any modifications, and reproduction in any medium, provided the original works properly cited. 

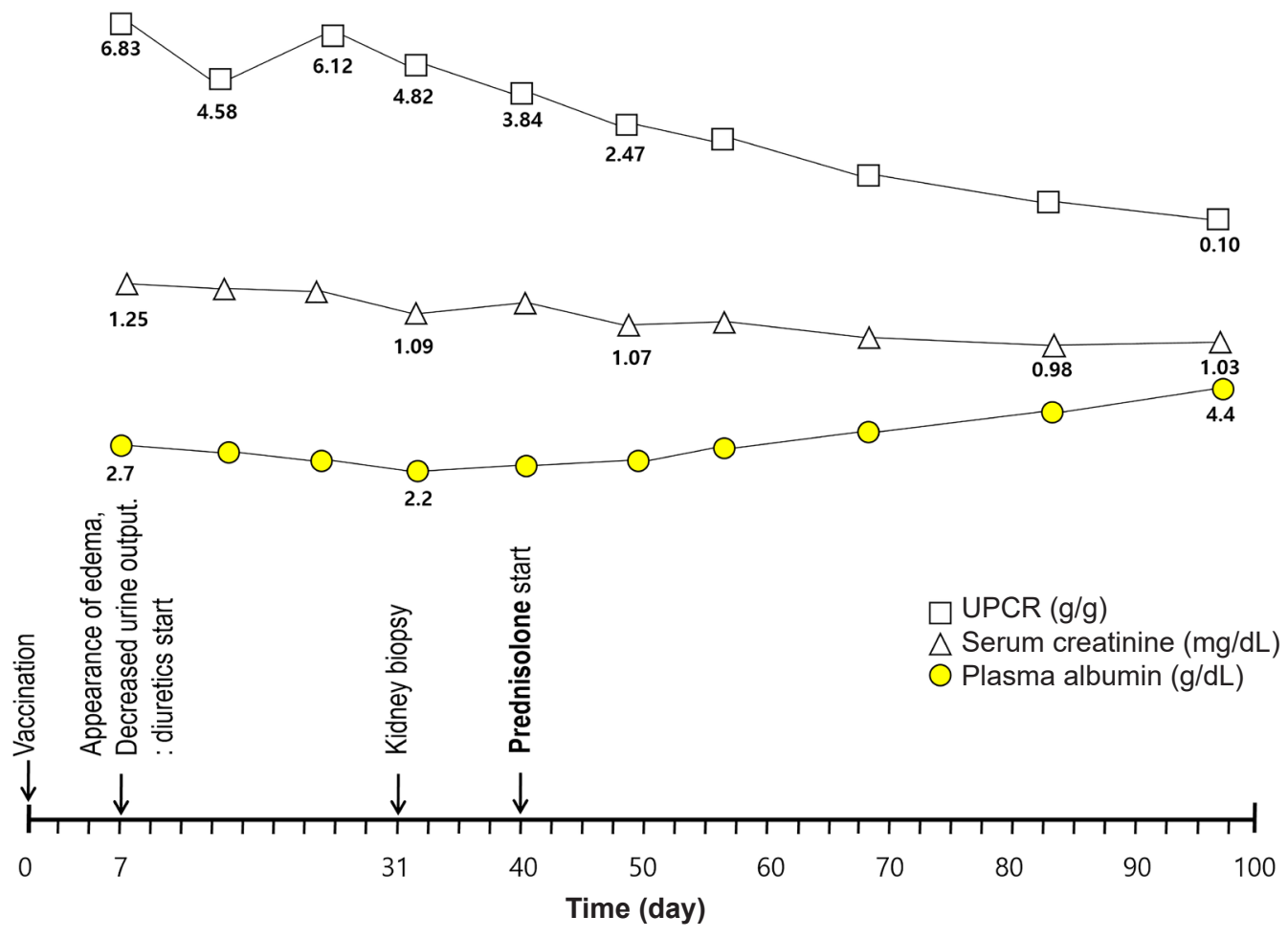

Figure 1. The timeline of clinical events from vaccination and edema progression.

UPCR, urine protein-to-creatinine ratio.

(5.0\%) exhibited FSGS with overlying podocyte proliferation (Fig. 2A). Electron microscopy revealed aggregates of RBCs in the capillary lumen with platelets and fibrin fibrils attached, which was suggestive of imminent microthrombus formation. The foot processes of the podocytes were diffusely effaced (Fig. 2B).

Based on these findings, we initiated treatment for FSGS with prednisolone ( $1 \mathrm{mg} / \mathrm{kg}$ daily), diuretics, angiotensin receptor blocker, and statin. Ten weeks after steroid treatment, the patient had no appreciable symptoms, and his laboratory results had normalized (serum albumin, $4.4 \mathrm{~g} /$ $\mathrm{dL}$ and creatinine, $1.03 \mathrm{mg} / \mathrm{dL}$ ). The urine protein-to-creatinine ratio was $0.10 \mathrm{~g} / \mathrm{g}$.

Most cases of GN following COVID-19 vaccine have been associated with administration of an mRNA vaccine [1]. Foreign mRNA can induce strong innate and adaptive immune responses [2,3]. Among these responses, the T-cell response provokes swift production of cytokines (such as interferon-gamma, tumor necrosis factor-alpha, and interleukin-2), which could trigger podocytopathies and GN [3].

To the best of our knowledge, this is the first report of $d e$ novo FSGS following COVID-19 mRNA vaccine. Although we could not demonstrate definitive causality, we believe that the FSGS in this case might have been caused by a COVID-19 mRNA vaccine for the following reasons. First, a healthy patient suddenly developed nephrotic syndrome 7 days after vaccination. The onset of disease at this time point was compatible with that mentioned in previous reports of COVID-19 mRNA vaccine triggering enhanced T follicular helper cell ( $\mathrm{Tfh}$ ) responses that peak 7 days after vaccination [2]. The mRNA vaccine-induced Tfh population and the associated cytokine system in susceptible patients can promote podocyte injury [2]. Second, previous reports $[4,5]$ have shown the development of recurrent FSGS lesions as early as 1 to 2 months after renal transplantation, which further support that the sclerotic lesions visible in this case could be a consequence of rapidly progressive podocytopathy triggered by a COVID-19 mRNA vaccine. Third, many viral infections, including COVID-19, are wellknown triggers for glomerular lesions and stimulate the onset of de novo and relapsing GN [2,6]. Because mRNA itself can be highly immunogenic, like an intact mRNA virus, 

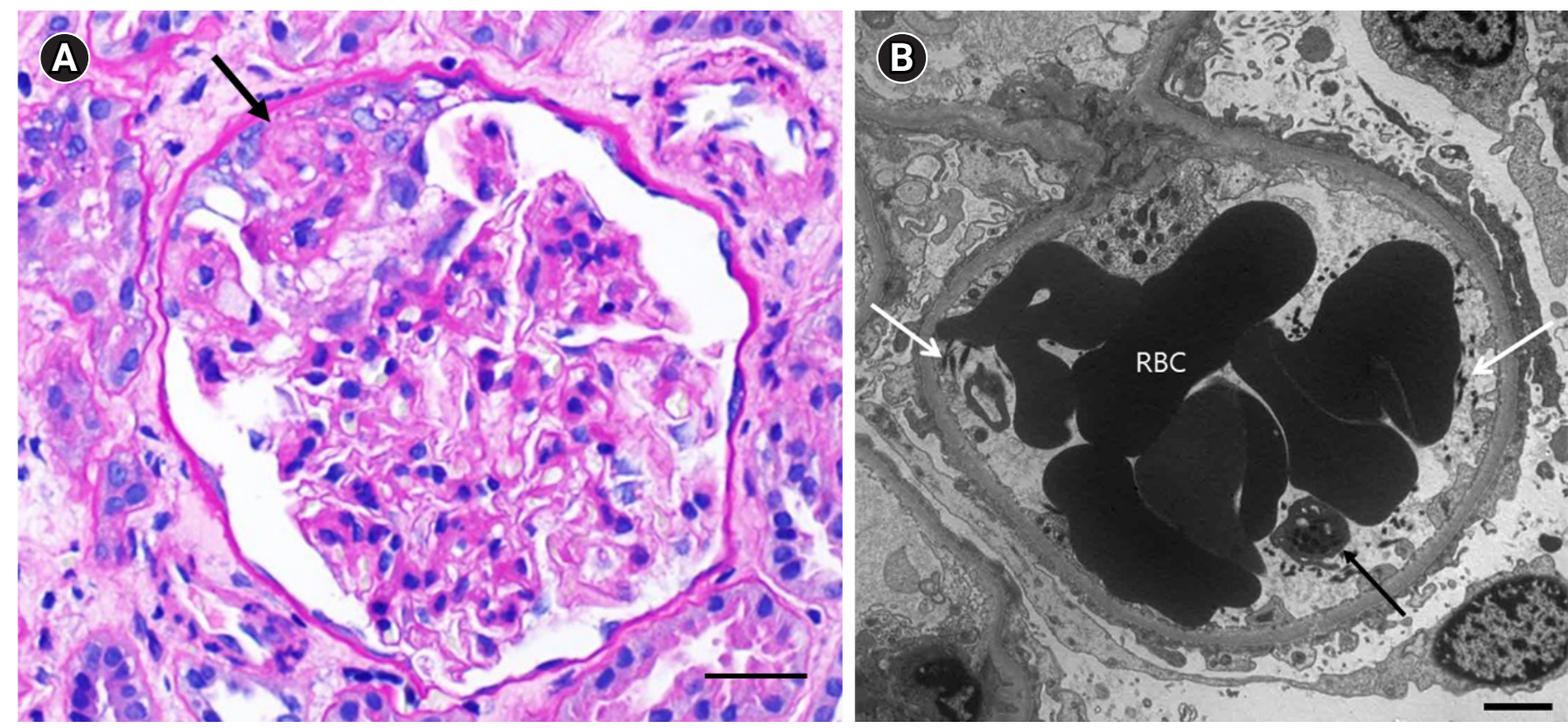

Figure 2. Kidney biopsy findings. (A) A periodic acid-Schiff-stained glomerulus showing a segmental area of sclerosis (arrow) with overlying podocyte proliferation. Scale bar $=25 \mu \mathrm{m}$. (B) An electron micrograph of a glomerulus showing aggregates of red blood cells (RBCs) in the capillary lumen with a platelet (black arrow) and fibrin fibrils (white arrows) attached. The foot processes of the podocyte are diffusely effaced. Scale bar $=2 \mu \mathrm{m}$.

COVID-19 mRNA vaccine-induced immune responses are analogous to COVID-19 virus-induced immune responses, both resulting in de novo and relapsing GN $[2,7]$. It is noteworthy that the FSGS in our case was a non-collapsing cellular variant, while COVID-19-induced FSGS is most commonly the collapsing type [7].

Our patient with no apparent underlying disease presented with FSGS after vaccination. We also acknowledge that increased patient awareness of symptoms after vaccination might lead to the recognition of previously undiagnosed kidney disease [2]. Although these associations do not prove causation, we believe that the abrupt onset of nephrotic syndrome following vaccination and the consistent time course of events indicate a direct role of mRNA vaccines $[2,6]$. Therefore, physicians should be aware of the possibility of FSGS development associated with vaccination. Further studies are needed to verify the cause of FSGS related to administration of COVID-19 vaccine and to study the risk factors for FSGS after COVID-19 immunization.

\section{Conflicts of interest}

The authors declare that there are no competing interests.

\section{Authors' contributions}

Conceptualization: JRK, SHB

Data curation: CAL, SY

Investigation: CAL, SY, EJK, JWS

Methodology: HSL, EJK, JWS

Visualization: CAL, HSL

Writing-original draft: CAL, HSL, JRK, SHB

Writing-review \& editing: CAL, HSL, JRK, SHB

All authors read and approved the final manuscript.

\section{ORCID}

Cho A Lim, https://orcid.org/0000-0002-3434-8801

Hyun Soon Lee, https://orcid.org/0000-0003-0682-3115

Songuk Yoon, https://orcid.org/0000-0002-9029-1918

Eun Jung Kim, https://orcid.org/0000-0002-4033-2769 Jang Won Seo, https://orcid.org/0000-0002-3495-5388 Ja-Ryong Koo, https://orcid.org/0000-0003-4245-2569 Seon Ha Baek, https://orcid.org/0000-0002-4751-9817 


\section{References}

1. Klomjit N, Alexander MP, Fervenza FC, et al. COVID-19 vaccination and glomerulonephritis. Kidney Int Rep 2021;6:2969-2978.

2. Li NL, Coates PT, Rovin BH. COVID-19 vaccination followed by activation of glomerular diseases: does association equal causation? Kidney Int 2021;100:959-965.

3. Bomback AS, Kudose S, D'Agati VD. De novo and relapsing glomerular diseases after COVID-19 vaccination: what do we know so far? Am J Kidney Dis 2021;78:477-480.

4. Cheong HI, Han HW, Park HW, et al. Early recurrent nephrotic syndrome after renal transplantation in children with focal segmental glomerulosclerosis. Nephrol Dial Transplant 2000;15:78-
81.

5. Uffing A, Pérez-Sáez MJ, Mazzali M, et al. Recurrence of FSGS after kidney transplantation in adults. Clin J Am Soc Nephrol 2020;15:247-256.

6. Dube GK, Benvenuto LJ, Batal I. Antineutrophil cytoplasmic autoantibody-associated glomerulonephritis following the Pfizer-BioNTech COVID-19 vaccine. Kidney Int Rep 2021;6:30873089.

7. May RM, Cassol C, Hannoudi A, et al. A multi-center retrospective cohort study defines the spectrum of kidney pathology in Coronavirus 2019 disease (COVID-19). Kidney Int 2021;100:1303-1315. 